\title{
Analisa Pengendalian Persediaan Dalam Hubungannya Dengan Efisiensi Biaya Pada Kandatel Ambon.
}

\author{
Sarifuddin \\ Universitas Pattimura \\ Merry Margareth Pelupessy \\ Universitas Pattimura \\ merrypelupessy77@gmail.com
}

\begin{abstract}
Abstrak
Studi ini bertujuan untuk melihat pengendalian persediaan dalam hubungannya dengan efisiensi biaya pada Kandatel Ambon. Dengan demikian maka Kandatel Ambon dijadikan sebagai objek penelitian serta dijadikan pula sebagai sumber data guna mendukung penulisan ini. Alat analisa yang digunakan untuk menganalisa penggendalian persediaan dalam hubungannya dengan efisiensi biaya maka digunakan alat analisa peramalan, Economic order quantity, reorder point, serta reorder cycle.Dari hasil perhitungan terlihat bahwa terlihat bahwa dengan menggunakan metode economic order quantity maka akan terjadi penghematan biaya sebesar Rp. 555.534.556 dengan pemesanan kembali sebanyak 3 kali. Untuk hal dimaksud maka pimpinan Kandatel Ambon perlu menggunakan metode perhitungan secara ekonomis dan bukan mengandalakan insting/permalan semata.Sehingga persediaan droop wire tidak menumpuk atau sebaliknya berkurang di gudang.
\end{abstract}

Kata Kunci: Persedian, Peramalan, Economic Order Quantity, Reorder Point, dan Reorder Cycle.

\section{Latar Belakang}

PT. TELKOM KANDATEL AMBON yang berlokasi di ibukota propinsi yaitu Kota Ambon adalah sutu perusahan yang berbentuk BUMN yang bergerak dibidang jasa telekomunikasi serta usaha - usaha lainnya yang dapat menunjang tecapainya tujuan perusahan yang telah direncanakan. Dalam melaksanakan usahanya, bagian logistic merupakan bagian yang terpenting yang ditunjang juga oleh bagian - bagian lainnya, antara lain bagian personalia, bagian keuangan, dan bagian pemasaran. Bahan baku dasar yang paling penting bagi kegiatan operasi perusahan ini adalah droop wire (DW, IX2/06mm) BW conector, jumper wire dan bahan pembantu lainnya . Dari sekian barang tersebut dan baha pembantu yang ada di sini hanya di bahas tentang droop wire (DW, IX2/06mm). Dalam melakukan pemasanan droopwire (DW, IX2/06mm) Kandatel Ambon hanya mengandalkan insting/peramalan semata. Hal ini disebabkan karena pada bagian logistic dalam melakukan permintaan terhadap droop wire (DW, IX2/06mm) tidak melakukan perhitungan yang mantap dan matematis dan hanya mengandalkan pengalaman periode sebelumnya sehingga seringkali mengakibatkan persediaan droop wire (DW, IX2/06mm) digudang kosong atau terjadi penumpukan sehingga berimbas pada inefisiensi biaya operasional perusahaan serta pengaruh juga pada kesinambungan kegiatan perusahaan. Untuk memenuhi kebutuhan droop wire (DW, IX2/06mm) perusahaan membuat DURK (daftar usulan rencanaa kegiatan) kemudian dari DURK disahkan menjadi DRK (daftar rencana kegiatan), setelah DRK 
kemudian dibuat DRP (daftar rencana pengadaan). Setelah dilakukan analisis secara saksama kemudian dilakukan pemesanan. Proses pemesanan hingga barang tiba ditujuan biasanya memakan waktu 6 hari tergantung proses pembahasan di Devisi VII Makassar. Biaya untuk setipa kali pemesanan adalah Rp. 700.000 dan biaya penyimpanan sebesar $12 \%$ dari setiap kali pesan. Adapun aktivitas perusahaan adalah 312 hari dimana dalam sesbulan perusahaan hanya beroperasi 26 hari.

Untuk mengetahui perkembangan pembelian dan pemakaian serta persediaan droop wire (DW, IX2/06mm) pada PT. Telkom Kandatel Ambon periode 2010-2014 dapat dilihat pada table berikut ini :

Tabel 1. Perkembangan Pembelian dan Pemakaian Droop Wire (DW.1X2/06 mm) Pada Kandatel Ambon Tahun 2014-2018 (dalam meter)

\begin{tabular}{|c|c|c|c|c|}
\hline Tahun & Stok Awal & Pembelian & Pemakaian & Stok Akhir \\
\hline 2014 & 5000 & 13000 & 10000 & 8000 \\
\hline 2015 & 8000 & 18000 & 14000 & 12000 \\
\hline 2016 & 12000 & 13000 & 12000 & 13000 \\
\hline 2017 & 13000 & 20000 & 28000 & -5000 \\
\hline 2018 & -5000 & 20000 & 14000 & 6000 \\
\hline
\end{tabular}

Sumber : Kandatel Ambon

Dari tabel diatas terlihat bahwa pada akhir periode tahin 2014 terdapat stok akhir sebanyak 5000 meter droop wire (DW, IX2/06mm) dan merupakan stok awal bagi tahun 2015, dan pembeliannya sebanyak 13000 meter dengan pemakian sebanyak 10000 meter, sehingga stok akhir tahun 2010 bertambah menjadi 8000 meter. Pada tahun 2016 terdapat stok awal sebanyak 8000 meter dan pembelian sebanyak 18000 meter sehingga persediaan pada tahun tersebut menjadi 20000 meter dan pemakaiannya sebanyak 14000 meter dan stok akhir pada periode tersebut 12000 meter dan merupakan stok awal bagi tahun 2017, dan pada periode tersebut dilakukan pembelian sebesar 13000 meter sehingga total persediaan droop wire (DW, IX2/06mm) pada tahun 2018 menjadi 25000 meter dan dalam pemakaiannya sebesar 12000 meter dan sisanya adalah 13000 meter pada akhir periode dan 13000 meter ini merupakan stok awal pada tahun 2018 ditambah dengan pembelian 10000 meter karena Kandatel Ambon merasa mempunyai persediaan stok awal sebesar 13000 meter padahal pemakaian pada periode tersebut sebanyak 28000 meter berarti terjadi kekurangan sebanyak 5000 meterdroop wire (DW, IX2/06mm) di dalam kegiatan proses produksinya. Pada tahun 2017 Kandatel Ambon sudah mengalami kekurangan stok droop wire (DW, IX2/06mm) melakukan pembelian sebanyak 20000 meter dan pemakaian sebesar 14000 meter sehingga stok akhir pada periode tersebut adalah 6000 meter.

Dari penjelasan diatas, jeaslah terlihat bahwa walaupun terdapat pesanan yang cukup banyak (terlihat dari jumlah pemakian yang terus meningkat dari tahun ke tahun) namun pihak manajemen belum mampu memprediksi ketersediaan bahan droop wire (DW, IX2/06mm) yang ada secara tepat dan matematyis sehingga seringkali terjadi penumpukan atau kekurangan stok digudang untuk kegiatan produksinya. Hal ini 
disebabkan karena didalam operasinya pihak manajemen selalu menggunakan ramalan / insting berdasarkan pengalaman periode sebelumnya.

\section{Landasan Teori}

\section{Pengertian Produksi dan Manejemen Produksi}

Menurut Sofyan Assauri (1979) Manajermen produksi menyatakan bahwa : "Produksi adalah segala kegiatan dalam menciptakan atau menambah kegunaan (utility) suatu barang atau jasa untuk kegiatan mana dibutuhkan faktor-faktor produksi yang dalam ilmu ekonomi berupa tanah, modal, tenaga kerja, skill (keahlian)",

Dalam bukunya manajemen produksi, Sutanto dan Indriyo (1980) mendefenisikan manajemen produksi sebagai "Suatu proses perenjanaan ,pengoperasian,pengarahan, pengkoordinasian, pengawasan yang dilakukan sejara timbal balik dalam hubungannya dengan memproduksi atau mengatur produksi barangbarang atau jasa-jasa dalam jumlah ,kualitas, harga, waktu, serta tempat tertentu sesuai dengan kebutuhan tertentu sesuai dengan kebutuhan konsumen untuk memperoleh profit atau keuntungan yang diharapkan.

Dari defenisi di atas, jelaslah bahwa dalam operasinya perusahan sangat membutuhkan suatu manejemen yang baik untuk mengelolah sumber daya- sumber daya yang ada di dalam suatu perusahaan sehingga menghasilkan suatu produk yang diinginkan oleh pemerintah konsumen .

\section{Persedian}

Sofyan Assury (1979) mendefenisikan persediaan sebagai "Persediaan adalah suatu aktiva yang meliputi barang-barang milik perusahaan dengan maksud untuk dijual dan lain-lain dalam suatu periode yang normal, atau persediaan bahan baku yang menunggu penggunaanya dalam suatu proses produksi."

\section{Pengendalian Persediaan}

Dalam hubungan dan kaitannya dengan pengendalian persediaan, maka ada beberapa ahli yang mendefenisikannya srebagai berikut, menurut Sujadi Prawirasentono (1997) mengemukakan "Pengendalian persediaan sebagai upaya menentukan besarnya tingkat persediaan dan mengendalikannya secara efisien dan efektif."

\section{Peramalan}

Menurut Sofyan Assury (1990) bahwa peramalan adalah "Seni dan ilmu dalam memprediksikan kejadian yang mungkin dihadapi pada masa yang akan datang.

Dengan memperhatikan defenisi diatas maka peramalan juga merupakan aspek yang cukup penting untuk diperhatikan perusahaan. Disamping itu peranan peramalan bagi perusaahaan juga sangat penting yaitu untuk menentukan kapan suatu peristiwa akan terjadi atau suatu kkebutuhan akan timbul sehingga dapat dipersiapkan tindakantindakan apa yang perlu dilakukan.

\section{Economy Order Quantity (EOQ)}

Ada beberapa faktor yang mempengaruhi persediaan antara lain :

1. Lead time (jarak antara barang dipesan hingga barang tiba ditangan pemesan).

2. Frekuensi penjualan selama satu periode. 
3. Dana yang tersedia.

4. Kualitas produk.

Dengan berpatokan pada penjelasan tersebut diatas, maka dalam pengendalian persediaan dan penentuian jumlah pesanan yang ekonomis maka KandatelAmbon sebaiknya menggunakan perhitungan analisa economic order quantity (EOQ) sebagai alat analisa dengan terlebih dahulu kita harus mengetahui apa yang dimaksudkan sebenarnya dengan EOQ.

Dalam bukunya persediaan, Model dan analisa maka Siswanto (1998) mengartikan EOQ atau jumlah pesanan yang ekonomis adalah "Model persediaan yang akan membantu manajemen untuk pengembilan keputusan unti yang harus dipesan agar tidak terjadi investasi yang berlebihan yang ditanamkan dalam persedian serta tidak mengalami kehabisan persediaan yang akan mengakibatkan proses produksi terhenti, penundaan pesanan, kehilangan laba yang potensial, serta kerugian karena kehilangan pelanggan."

Dengan menggunakan metode EOQ maka perusahaan akan dapat menetapkan berapa besarnya pesanan setiap kali yang paling ekonomis. Oleh karena itu maka model EOQ hanya dapat digunakan jika :

- Jumlah kebutuhan ataubarang sudah ditemntukan terlebih dahulu secara pasti untuk penggunaan selama periode tertentu.

- Penggunaan bahan selalu daalam tingkat yang konstan secara continue.

- Pesanan yang diterima pada saat tingkat persediaan sama dengan nol atau diatas persediaan yang minimal.

- Harga barang /bahan tidak berubah-ubah pada periode tersebut.

- Biaya pesanan adalah konstan.

- Biaya penyimpanan per unit adalah tetap

Walaupun sedikit banyaknya sangat bermanfaat bagi perusahaan, model EOQ juga memiliki kelemahan-kelamahan yang pada prinsipnya sealalu bertentangan dengan situasi dan kondisi yang ada pada perusahan. Kelemahan-kelemahan itu antara lain:

Menurut rumus EOQ maka harga barang berapapun dibeli/dipesan dianggap bahwa harga per unitnya adalah sama.

$>$ Rumus EOQ tidak memperhatikan tingkat kerusakan pada bahan/produk, padahal tingkat kerusakan sering dijumpai dalam setiap produk yang akan dipesan/digunakan.

$>$ Rumus EOQ tidak memperhatikan tingkat bunga, padahal biaya bunga modal tidak boleh dianggap kecil.

\section{Reorder Point}

Bambang Rianto (1980) mendefenisikan reorder point sebagai "Suatu titik dimana harus dilakukan pemesanan kembali sedemikian rupa sehingga kedatangan/penerimaan material yang dipesan itu adalah tepat pada waktu dimana persediaan diatas safety stock (persediaan pengaman) sama dengan nol."

Dari defenisi diatas maka untuk menentukan reorder point maka haruslah menentukan empat variable utama yaitu :

1. Lead time, ( L )

2. Tingkat kebutuhan per hari ( $U$ )

3. Safety Stock (D) 
4. Kebutuhan bahan tersebut setiap waktu ( Y )

Secara kasar reorder point merupakan hasil kali L dan U di tambah dengan sejumlah tertentu sebagai persediaan pengaman ( Safety stock). Besarnya safety stock tergantung pada kebijaksanaan masing-masing perusahaan.

\section{Reorder Cycle}

Yang dimaksud dengan reorder cycle atau daur pemesanan ulang menurut Siswanto (1985) adalah " Periode sejak unit yang dipesan ( Q ) dating hingga saat datangnya unit yang dipesan berikutnya yang mana tepat sama dengan saat habisnya persediaan".

Periode waktu disini dapat dinyatakan dalam berbagai satuan, misalnya tahun, bulan, minggu dan hari tergantung pada satuan mana yang ingin di kehendaki.

\section{Hipotesa}

Berdasarkan permasalahan diatas maka hipotesa yang digunakan adalah :"diduga dengan penerapan sistim pengedaliaan yang tepat maka perusahaan dapat mengefisiensi biaya persediaan."

\section{Metodologi Penelitian}

\section{Lokasi / Objek Penelitian}

Yang menjadi lokasi dalam penelitian ini adalah KANDATEL Ambon yang letaknya sangat strategis di pusat atau tengah kota.

\section{Jenis Data}

Data yang digunakan untuk menganalisa persediaan adalah data perkembangan persediaan Kandatel Ambon selama lima tahun terkahir.

\section{Sumber Data}

Sumber data yang digunakan dalam penulisan ini adalah :

1. Data primer yaitu data langsung dari perusahaan yang berupa laporan persediaan sejarah singkat perusahaan, kondisi perusahan dan struktur organisasi serta sistim operasional.

2. Data sekunder yaitu data yang diperoleh dari luar perusahaan untuk menunjang penulisan ini dalam bentuk literature - literature yang berisikan peralatan analisa.

\section{Teknik Pengambilan Data.}

Pengambilan data dilakukan dengan mengadakan wawancara langsung dengan pihak - pihak yang bersangkutan dalam perusahaan. Dan penelitian kepustakaan dengan mengumpulkan data informasi yang ada pada perusahaan.

\section{Teknik Analisa}

Dalam memecahkan masalah-masalah diatas maka digunakan beberapa analisa yaitu :

\section{Analisa Kuantitatif}

- Analisa peramalan

- Analisa economic order quantity

- Analisa biaya ekonomis 
- Reorder point

- Reorder cycle

\section{Hasil dan Pembahasan}

\section{Analisa peramalan}

Analisa peramalan di pakai untuk meramalkan berapa banyak pemakaian dimasa yang akan datang. Analisa yang digunakan adalah analisa least square atau analisa trend garis lurus. Dapat dilihat pada tabel berikut ini :

Tabel 2. Trend Pemakaian Droop Wire (DW, IX2/06mm) Tahun 2014-2018 (dalam meter)

\begin{tabular}{|c|c|c|c|c|}
\hline Tahun & $\begin{array}{c}\text { Pemakaian } \\
\text { (Y) }\end{array}$ & $\mathbf{X}$ & $\mathbf{Y}$ & $\mathbf{X Y}$ \\
\hline 2014 & 10000 & -2 & -20000 & 4 \\
2015 & 14000 & -1 & -14000 & 2 \\
2016 & 12000 & 0 & 0 & 0 \\
2017 & 28000 & 1 & 28000 & 2 \\
2018 & 14000 & 2 & 28000 & 4 \\
\hline$\Sigma$ & 78000 & 0 & 22000 & 10 \\
\hline
\end{tabular}

Sumber: Hasil Perhitungan

Dari perhitungan tersebut diatas, diperoleh persamaan linier sebagai beikut :

$$
\mathrm{Y}=15.600+22.000(\mathrm{x})
$$

Oleh karena itu maka ramalan kebutuhan untuk periode tahun ke-n adalah sebagai berikut :

Tahun $2013=22.220$

Tahun $2014=28.800$

Tahun $2015=35.400$

Tahun $2016=42.000$

Tahun $2017=48.600$

Dengan adanya tingkat pemakain berdasarkan ramalan datas, maka perusahaan dapat mengantisipasi tindakan-tindakan sebagai berikut :

1. Menentukan jumlah pesanan yang ekonomis.

2. Kapan perusahaan mengadakan pemesanan kembali.

3. Menggunakan analisa biaya untukmendapatkan efieinsi.

\section{Analisa Economic Order Quantity (EOQ)}

Analisa ini digunakan untuk mengetahui jumlah pesanan droop wire (DW, IX2/06mm) yang paling ekonomis. 
Asumis-asumsi yang diperhatikan antara lain :

1. Besarnya permitaan/pemakian akan produk diketahui dengan pasti.

2. Biaya pemasanan untuk setiap kali pesan adalah konstan selama periode analisa.

3. Biaya penyimpanan per unit adalah konstan untuk setiap periode analisa.

4. Harga perunit produk adaah konstan.

5. Produk yang dipesan/dibeli selalu tersedia dipasar.

Cara-cara yang diperoleh dari perusahaan antara lain :

1. Biaya pemesanan (S) adalah : Rp.7.000/meter

2. Biaya penyimpanan $(\mathrm{H})$ adalah $: 12 \%$ per unit

3. Besarnya pesanan untuk setiap kali pesan adalah : 5000

4. Frekuensi pesanan $(\mathrm{N})$ adalah $: 4$ kali/periode

Berdasarkan data-data diatas maka pesanan yang paling ekonomi bagi Kandatel Ambon dapat dinalisa dengan menggunakan periode tahun 2013 sebagai alat analisa yaitu :

$$
\begin{array}{ll}
\text { Qopt }=\sqrt{\frac{2 D S}{H}} & \\
\text { D (permintaan/periode) } & =20000 \text { meter } \\
\text { S (Biaya pemesanan/pesanan) } & =\text { Rp. } 35.000 .000 \\
\text { H (biaya penyimpanan/periode }) & =\text { Rp. } 2.000 .000 \\
\text { Q opt } & =8.360 \text { meter }
\end{array}
$$

Dengan frekuensi pesanann $(\mathrm{N})$ sebanyak :

$$
\begin{aligned}
\mathrm{N} & =\frac{D}{Q} X 1 \\
\mathrm{~N} & =3 \text { (dibulatkan) }
\end{aligned}
$$

\section{Analisa Biaya Ekonomis}

A. Menurut kebijakan perusahaan

1. Frekuensi pesanan (N) 4 dalam setahun adalah : $20.000: 4=5.000$ meter

2. Persediaan rata-rata $=1 / 2$ dari besarnya pesanan tiap kali pesan yaitu : $5000: 2=2500$ meter

3. Jumlah biaya yang dikorbankan untuk pengadaan barang adalah
a. Biaya pesanan $\quad=4 \times 7000$
$=$ Rp. 28.000
b. $\begin{aligned} \text { Biaya penyimpanan }=2500 \times \text { Rp } 2.000 .000 & =\underline{\text { Rp. } 5.000 .000 .000} \\ \text { Jumlah }= & \text { Rp. } 5.000 .028 .000\end{aligned}$ 
B Menurut Analisa Economic Order Quantity (EOQ)

1. Frekuensi pesanan (N) 3 dalam setahun adalah : $20.000: 3=6666,6$ meter

2. Persediaan rata-rata $=1 / 2$ dari besarnya pesanan tiap kali pesan yaitu : $6666,6: 3=2222,2$ meter

3. Jumlah biaya yang dikorbankan untuk pengadaan barang adalah
a. Biaya pesanan
$=3 \times 7000$
$=$ Rp. 21.000
b. Biaya penyimpanan $=2222,2 \times \operatorname{Rp} 2.000 .000=\underline{\mathrm{Rp}} \cdot \mathbf{4 . 4 4 4 . 4 4 4 . 4 4 4}$
Jumlah $=$ Rp. 4.444.465.444

Berdasarkan perhitungan tersebut ditas maka akan terlihat efisiensi biaya sebesar Rp.5.000.028.000 - Rp.4.444.465.444 = Rp. 555.534 .556

Dengan demikian jika biaya penyimpanan dan biaya pemesanan diasumsikan tidak berubah atau konstan pada setiap periode produksi maka ramalan terhadap jumlah persediaan yang paling ekonomis atau yang harus dipesan atau harus dibeli untuk dijadikan sediaan bagi Kandatel Ambon pada periode tahun 2013 adalah sebagai berikut :

Tahun 2017

Q opt=8775 meter (dibulatkan)

Tahun 2018

$\mathrm{Q}$ opt $=10.039$ meter

\section{Analisa Jumlah Pesanan Kembali (Reorder Point)}

Data-data yang diperoleh dari perusahaan :

1. Lead Time (L) adalah 6 hari

2. Level of service adalah $99 \%$

3. Aktivitas perusahaan dalam setahun adalah : 312 hari, dimana dalam sebulan perusahaan beroperasi selama 26 hari.

Tabel 3. Data Pemakaian Droop Wire (DW, IX2/06mm) Pada Tahun 2017

\begin{tabular}{|l|c|c|c|c|}
\hline \multicolumn{1}{|c|}{ Bulan } & \multicolumn{2}{c|}{ Pemakaian } & $(\gamma-\bar{\gamma})$ & $(\gamma \chi \overline{\gamma i})$ \\
\cline { 3 - 3 } & Meter & \% & & \\
\hline Januari & 2372 & 8,47 & 39 & 1521 \\
Pebruari & 3419 & 12,2 & 1086 & 1,17936 \\
Maret & 974 & 3,47 & 1359 & 1.846 .881 \\
April & 890 & 3,17 & 1443 & 2.082 .249 \\
Mei & 350 & 1,25 & 1983 & 3.932 .289 \\
Juni & 4785 & 17,08 & 2452 & 6.017 .209 \\
Juli & 6420 & 22,93 & 4087 & 16.703 .569 \\
Agustus & 5311 & 18,96 & 2978 & 8.868 .484 \\
September & 980 & 3,5 & 1353 & 1.830 .609 \\
Oktober & 742 & 2,65 & 2259 & 5.103 .081 \\
Nopember & 564 & 2,01 & 1769 & 3.129 .361 \\
Desember & 1193 & 4,26 & 1140 & 1.299 .600 \\
\hline \multicolumn{1}{|c|}{$\Sigma$} & 28000 & 100 & 0 & 51.994 .749 \\
\hline
\end{tabular}

Sumber : Data Hasil Perhitungan 
Dari hasil perhitungan diatas, maka diperoleh :

1. Rata-rata pemakian droop wire (DW, IX2/06mm) per bulan :

$$
\begin{aligned}
& \bar{Y}=\frac{\sum Y}{n} x 1 \\
& =2333 \text { meter (dibulatkan) }
\end{aligned}
$$

2. Standar deviasi pemakaian bulanan adalah :

$$
\begin{aligned}
\sqrt{d i} & =\sqrt{\frac{\left(\gamma-\overline{\gamma)^{2}}\right.}{n-1}} \\
& =2174,1 \text { meter }
\end{aligned}
$$

3. Rata-rata pemakaian droop wire (DW, IX2/06mm) per hari adalah :

$$
\begin{aligned}
\bar{d} & =\frac{D}{N} x 1 \\
& =89,74 \text { meter }
\end{aligned}
$$

4. Pemakian droop wire (DW, IX2/06mm) selama lead time adalah :

$$
\begin{aligned}
\bar{d} L & =\bar{d} x L \\
& =89,74 \times 6 \\
\bar{d} L & =538,46 \text { meter }
\end{aligned}
$$

5. Standar deviasi selama lead time adalah :

$$
\begin{aligned}
& \sqrt{\mu}=\sqrt{\sum_{i=1}^{L} \sqrt{d i^{2}}} \\
& \sqrt{\mu}=1.065 \text { meter }
\end{aligned}
$$

6. Safety stock atau cadangan persediaan adalah :

Ss $=\partial X \sqrt{\mu}$

$\mathrm{Ss}=2456,6$ meter

7. Jadi Reorder Point atau titik pemesanan kembali adalah :

$$
\begin{aligned}
\mathrm{R} & =\bar{d} L+S s \\
& =538,46+2456,6 \\
& =2.995,06 \text { meter }
\end{aligned}
$$


Tabel 4. Varians, Safety Stock dan Reorder PointPada Kandatel Ambon (dalam meter)

\begin{tabular}{|l|l|l|}
\hline No. & Pengendalian Persediaan & Jumlah \\
\hline 1. & Deviasi pemakian bulanan (di) & 2174,1 meter \\
2. & Pemakiaan harian (d) & 89,74 meter \\
3. & Pemakaian selama lead time (dL) & 538,46 meter \\
4. & Deviasi selama lead time $(\mu)$ & 1.065 meter \\
5. & Safety stock $(\mathrm{Ss})$ & 2456,6 meter \\
6. & Reorder point $(\mathrm{R})$ & $2.995,06$ meter \\
\hline
\end{tabular}

Sumber : Hasil Perhitungan

\section{Daur Pemesanan Ulang (Reorder Cycle)}

Reorder cycle yaitu metode yang digunakan untuk menentukan periode sejak unit yang dipesan datang hingga saat datangnya unit yang dipesan berikutnya, yang dihitung dengan menggunakan rumus sebagai berikut :

$\mathrm{Y}=\frac{1}{N} \mathrm{X}$ satuan periode waktu

$\begin{array}{cl}\text { Maka Y } & =\frac{1}{N} X 1 \text { tahun } \\ \text { Y } & =156 \text { hari }\end{array}$

\section{Kesimpulan dan Saran \\ Kesimpulan}

1. Yang dimaksudkan dengan persediaan adalah suatu aktiva yang meliputi barang-barang milik perusahaandengan maksud untuk dijual dalam suatu periode usaha tertantu atau persediaan barang-barang yang masih dalam pengerjaan atau proses produksi, ataupun persediaan bahan baku yang menunggu penggunaannya dalam proses produksi.

2. Proses pemesanan hingga barang tiba ditujuan biasanya memakan waktu 6 hari tergantung proses pembahasan di Devisi VII Makassar. Biaya untuk setipa kali pemesanan adalah Rp. 7.000 / meter dan biaya penyimpanan sebesar $12 \%$ dari setiap kali pesan. Adapun aktivitas perusahaan adalah 312 hari dimana dalam sesbulan perusahaan hanya beroperasi 26 hari.

3. Berdasarkan metode EOQ maka telihat adanya efisiensi biaya sebesar Rp. 555.534.556. Dibandingkan dengan menggunakan kebijaksanaan perusahaan yang melakukan pemesanan dalam satu tahun sebanyak 4 kali dalam setahun. Sedangkan dengan menggunakan metode EOQ maka perusahaan sebaiknya melakukan pemesanan dalam satahun seharusnya sebanyak 3 kali. 


\section{Saran}

1. Pihak KANDATEL Ambon perlu merubah kebijakan pemasanan barang dengan menggunakan metode yang bersifat matematis dan bukan mengandalkan peramalan/insting semata. Sehingga pemakian dan pemesanan selisihnya tidak terlalu besar

2. Dengan menggunakan pendekatan matematika ekonomis maka KANDATEL Ambon akan terjadi efisiensi biaya. Sehingga dapat menekan biaya produksi yang seharusnya dialokasikan untuk keperluan lainnya.

3. Pihak Kandatel Ambon agar dalam melakukan pemesanan droop wire (DW, IX2/06mm) dapat melakukan perhitungan dan teknik pesanan secara matematis sehingga persediaan droop wire (DW, IX2/06mm) selalu ada jika dibutuhkan, namun tidak berlebihan sehingga terjadi penumpukan di gudang.

\section{Daftar Pustaka}

Alex. S. Nitisemito, Pembelanjaan Perusahaan, Cetakan Ke enam, Penerbit Ghalia Indonesia.

Agus Ahyari, Manajemen Produksi dan Pengendalian Produksi, Edisi Keempat, BP_FE, Jogjakarta, 1986.

Bambang Riyanto, Dasar-Dasar Pembelanjaan Perusahaan, Edisi Kedua, Cetakan Ke enam, Jogjakarta, BPFE-UGM, 1980.

Basu Swastha, DH, Pengantar Ekonomi Perusahaan Modern, Edisi Kedua, Cetakan I, Yoyakarta, Penerbit Liberthy, Tahun 1982..

Franklin G. Moore,Manufacturing Management, Third Edition. Illionois, Irwin, Inc, 1961.

Freddy Rangkkuti, Manajemen Persdiaan, Edisi Kedua, Cetakan II, PT. RGP Jakarta, Tahun 1996.

Panitia Istilah Manajemen, Kamus Istilah Manajemen, Edisi Kedua, LPPM Balai Aksara 1981.

Richard B. Chase dan N.J. Aquilano, Production and Operational Management, Fourth Edition, Home work Illionois, Irwin, Inc, 1985.

Siswanto, Persediaan, Model, dan Analisa, Edisi Pertama, Cetakan Pertama, Jojakarta, Penerbit ANDI OFFSET, 1985,

Reksohadirpojo dan Harsono, Perencanaan Pengawasan, Jogjakarta,Penerbit FE_UGM, 1982,

Philip Kotler, Manajemen Pemasaran, Edisi Kedua, Jakarta, Penerbit Airlangga, 1989.

Sofyan Assauri, Manajemen Produksi, Edisi Ketiga, Jakarata, LP-FEUI, Tahun 1979

Sofyan Assury, Teknik dan Metode Peramalan, Edisi Pertama,Jakarta, Penerbit FE_UI. 1990

Sukanto, R, dan Indriyo G, Manajemen Produksi, Edisi Pertama, FE-UGM, Yogyakarta, Tahun 1990.

Sujadi Prawirasentono, Manajemen Produksi dan Operasi, Cetakan I, Terbitan Bumi Aksara, 1997.

T. Hani Handoko, Dasar-Dasar Manajemen Produksi dan Operasi, Edisi Pertama, BPFE-UGM 1995 